\title{
Tetanus in a child as a result of the vaccination schedule violation - a case report
}

\author{
Halyna Pavlyshyn, Ivanna Horishna, Viktoriia Slyva*
}

A clinical case of generalized tetanus in a preschooler with vaccination schedule noncompliance was analyzed. Clinical signs of generalized severe tetanus are presented. Modern approaches to the treatment of such patients, effectiveness and promises of therapy are shown.

Key words: TETANUS; CHILDREN; TREATMENT

\section{INTRODUCTION}

According the World Health Organisation (WHO) data, Ukraine was among the top eight countries with the lowest level of immunization coverage in children in 2016-2017. Countries like Nigeria, Somalia, South Sudan, Equatorial Guinea, Central African Republic, Chad and Syria were represented together with Ukraine in this list with less than $50 \%$ of infants completely immunized against diphtheria, tetanus and pertussis (DTP) (Figure 1, 2 and 3) (1, 2). By August 2018 , only $48.5 \%$ of infants were vaccinated against tuberculosis, 36.1\% against polio, 53.8\% against measles, $35.5 \%$ against hepatitis $B$, and $37.2 \%$ against diphtheria and tetanus. The immunization coverage in the Ternopil region is the lowest one (3).

Therefore, Ukrainian children are susceptible to diseases that have been forgotten elsewhere in the developed world. Tetanus is one such disease.

\section{CASE REPORT}

There were two cases of generalized tetanus in preschoolers in Ternopil region, Ukraine, in 2016-2017. We present one of them. A 5-year-old child had several superficial skin traumas during the previous month. A forehead trauma occurred four weeks, left knee trauma two weeks, and left palm trauma three days prior to hospital admission. At admission, some excoriations were present from the first and second trauma, and an inflamed wound on the left palm.
The parents had asked for medical care on the $3^{\text {rd }}$ day following the last trauma. The complaints included impaired swallowing, inability to open the mouth, face asymmetry, and forced position of the head with neck muscle hypertonia. Because of that, they were referred to an ear-nosethroat (ENT) specialist, and later to the Intensive Care Unit (ICU) of the Ternopil Regional Children's Clinical Hospital. The child had not been immunized because of parental beliefs.

The patient's general condition was severe at the time of hospitalization because of neurological symptoms that included forced position of the head, which was bent back, asymmetry of the eye slots, severe trismus, risus sardonicus, and painful nuchal rigidity that became more intense during medical manipulations. His skin temperature was $37.5^{\circ} \mathrm{C}$, respiratory rate 20 per minute, cardiac rate 120 per minute, blood oxygenation 98\%. Breath sound was vesicular with stridorous phenomena. Cardiac tones were rhythmic, a bit weak. The abdomen was sunken with the anterior abdominal wall muscle rigidity and spasms elicited on palpation.

Generalized tetanus with a severe course was diagnosed on the basis of history and clinical signs.

\footnotetext{
* I. Ya. Horbachevsky Ternopil State Medical University, Department of Pediatrics No.2, Ternopil, Ukraine
}

\section{Correspondence to:}

Viktoriia Slyva, MD, PhD, Department of Pediatrics No. 2, I. Ya.

Horbachevsky Ternopil State Medical University, 8/112, Zluky Str., Ternopil, Ukraine, e-mail:vsliva@hotmail.com

Primljeno/Received: 24. 10. 2018., Prihvaćeno/Accepted: 18. 1. 2019. 


\section{Total tetanus global annual reported cases and DTP3 coverage, 1980-2016}

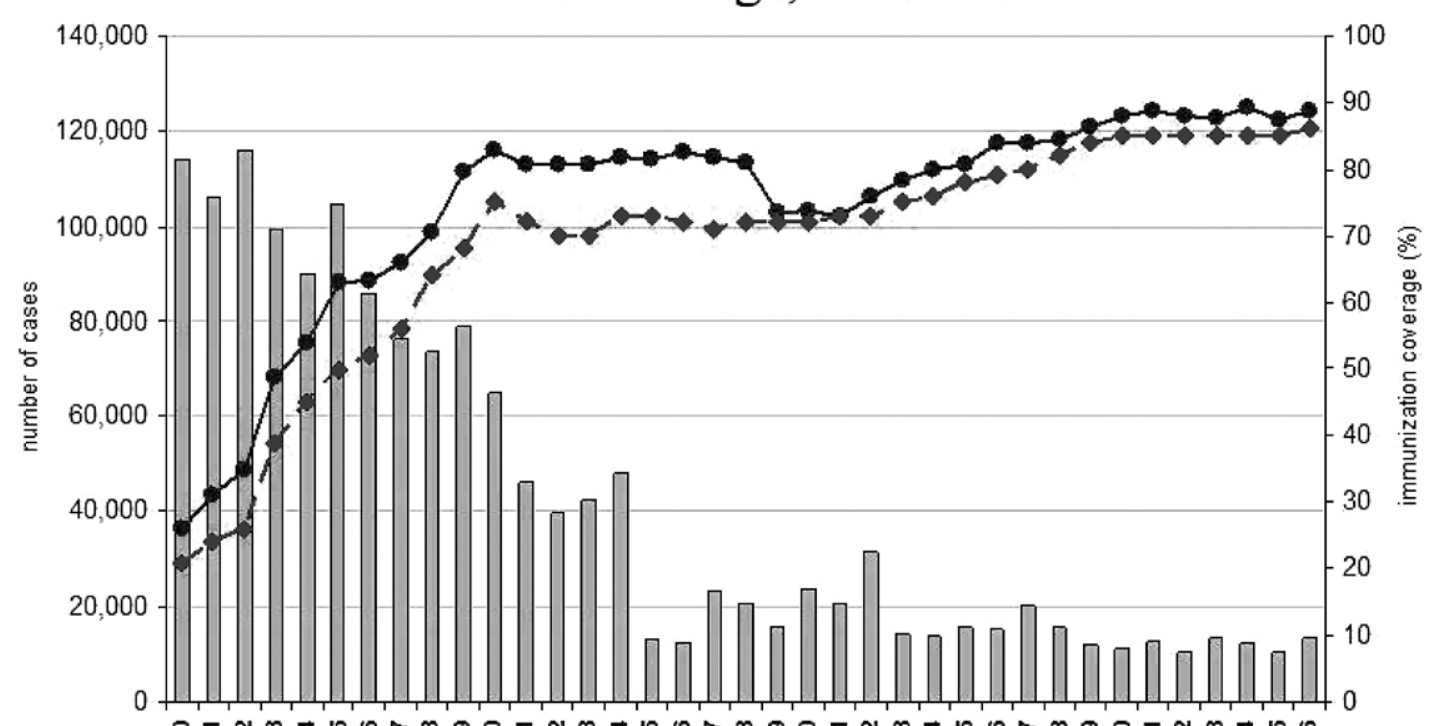

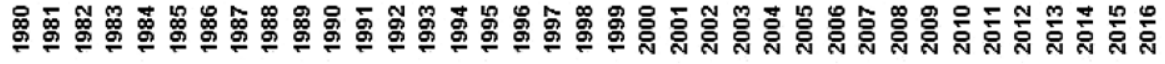

\section{Number of cases $\rightarrow$ Official coverage $-\leftarrow$ WHO/UNICEF estimates}

Source: WHOAVB database, 2017

194 WHO Member States.

Data as of 19 July 2017

FIGURE 1. WHO and UNICEF estimates of total tetanus global annually reported cases and DPT coverage, 1980-2016 (DTP3 $=3^{\text {rd }}$ dose of DTP vaccine according to vaccination schedule that should be administered at 6 months).

Source: http://www.who.int/immunization/monitoring_surveillance/burden/vpd/surveillance_type/passive/tetanus/en/

The patient was treated according to the Order of the Healthcare Ministry of Ukraine No. 198 as of August 5, 1999 (4). Equine antitetanus serum, 15,000 IU (1,000 IU/kg), was injected intravenously during seven hours after hospital admission. Because of tetanus immunoglobulin shortage, the patient also received normal human immunoglobulin intravenously, $70 \mathrm{~mL}(4 \mathrm{~mL} / \mathrm{kg})$ for five days (5). Antibacterial (metronidazole, ampicillin + sulbactam) and anticonvulsive therapy (diazepam) in adequate doses was also prescribed.

However, 10 hours after hospital admission, opisthotonus developed together with respiratory failure that needed artificial ventilatory support.

Thiopental sodium (2 mg/kg), later diprofol (0.3-0.4-0.8 mg/ $\mathrm{kg} / \mathrm{h}$ ) and morphine for anaesthesia and anticonvulsive therapy intensification were prescribed due to a series of clonic convulsions resistant to diazepam. The repeat, second dose of tetanus toxoid of 15,000 IU intravenously and tetanus immunoglobulin 2,500 IU intramuscularly were in- jected on hospital day five because of continuous clonic convulsions and temperature $\left(38.5-38.9^{\circ} \mathrm{C}\right)$ resistant to antipyretic medicine. The patient's condition remained severe but stable for the next five days; the frequency of seizures decreased, but they relapsed on days 10-11 of treatment requiring heroic doses of anticonvulsive therapy and tetanus immunoglobulin in a dose of 2,750 IU. Tracheostomy was done.

Positive dynamics started on day 14 ; the number and intensity of seizures decreased, muscular pain decreased, risus sardonicus disappeared. The dose and frequency of anticonvulsive therapy was decreased. The patient could open his mouth more widely, could take more food enterally, defecate and urinate spontaneously. However, his body temperature was subfebrile, there was a large amount of mucous and serous secretions in the airways that needed frequent aspirations. Ventilation was changed to auxiliary ventilator support on day 21 of treatment. By day 30, he 


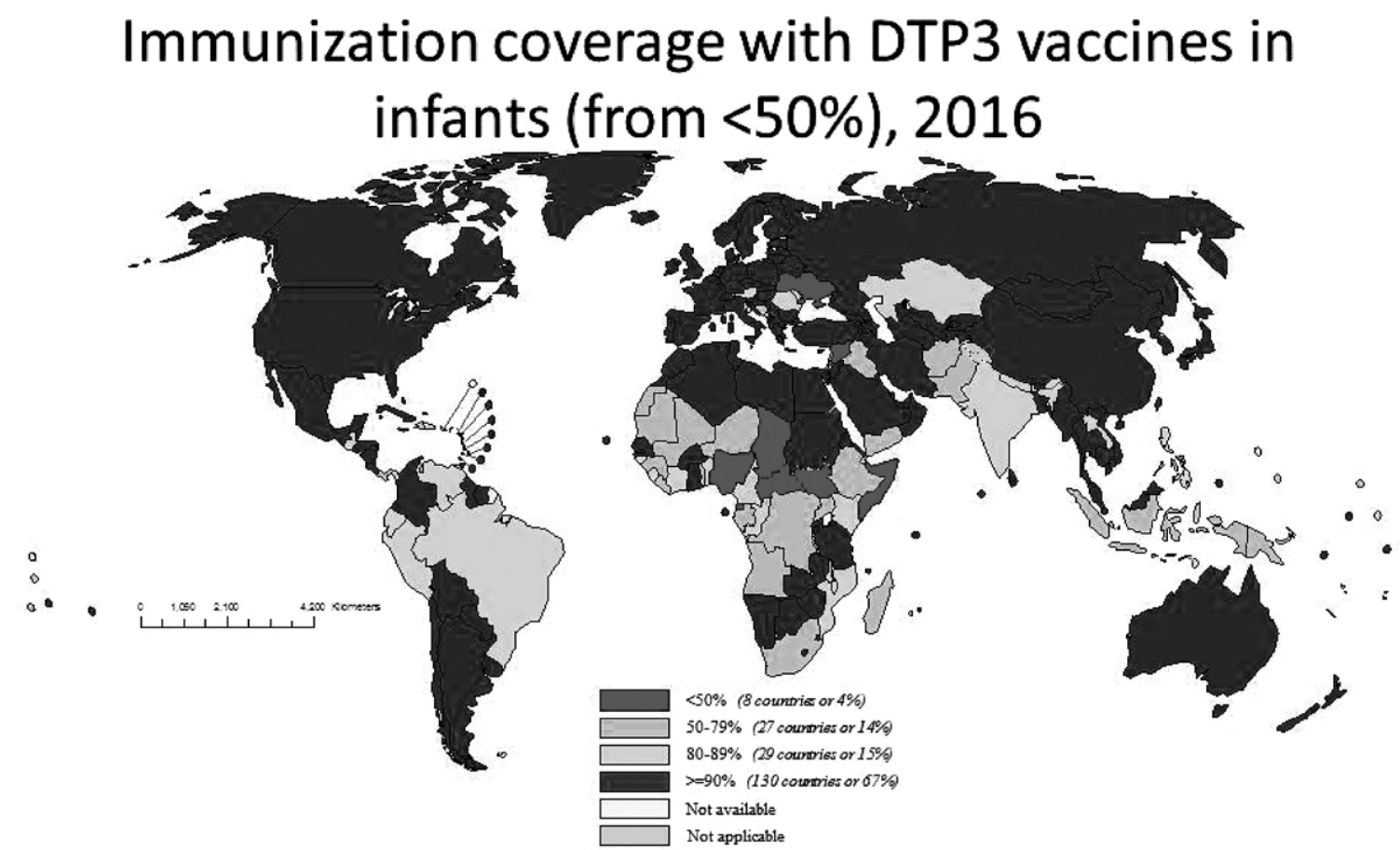

Source: WHO/UNICEF coverage estimates 2016 revision, July 2017. Map production: Imminization Vaccines and Biologicals. (NB). World Heath Organization. 194 WHO Member States. Date of slide: 19 July 2017

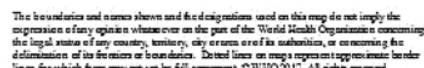

FIGURE 2. WHO and UNICEF estimates of national immunization coverage by DTP3 in 2016 (DTP3 $=3^{\text {rd }}$ dose of DTP vaccine according to vaccination schedule that should be administered at 6 months).

Source: http://www.who.int/immunization/monitoring_surveillance/burden/vpd/surveillance_type/passive/tetanus/en/

UKR - DTP3

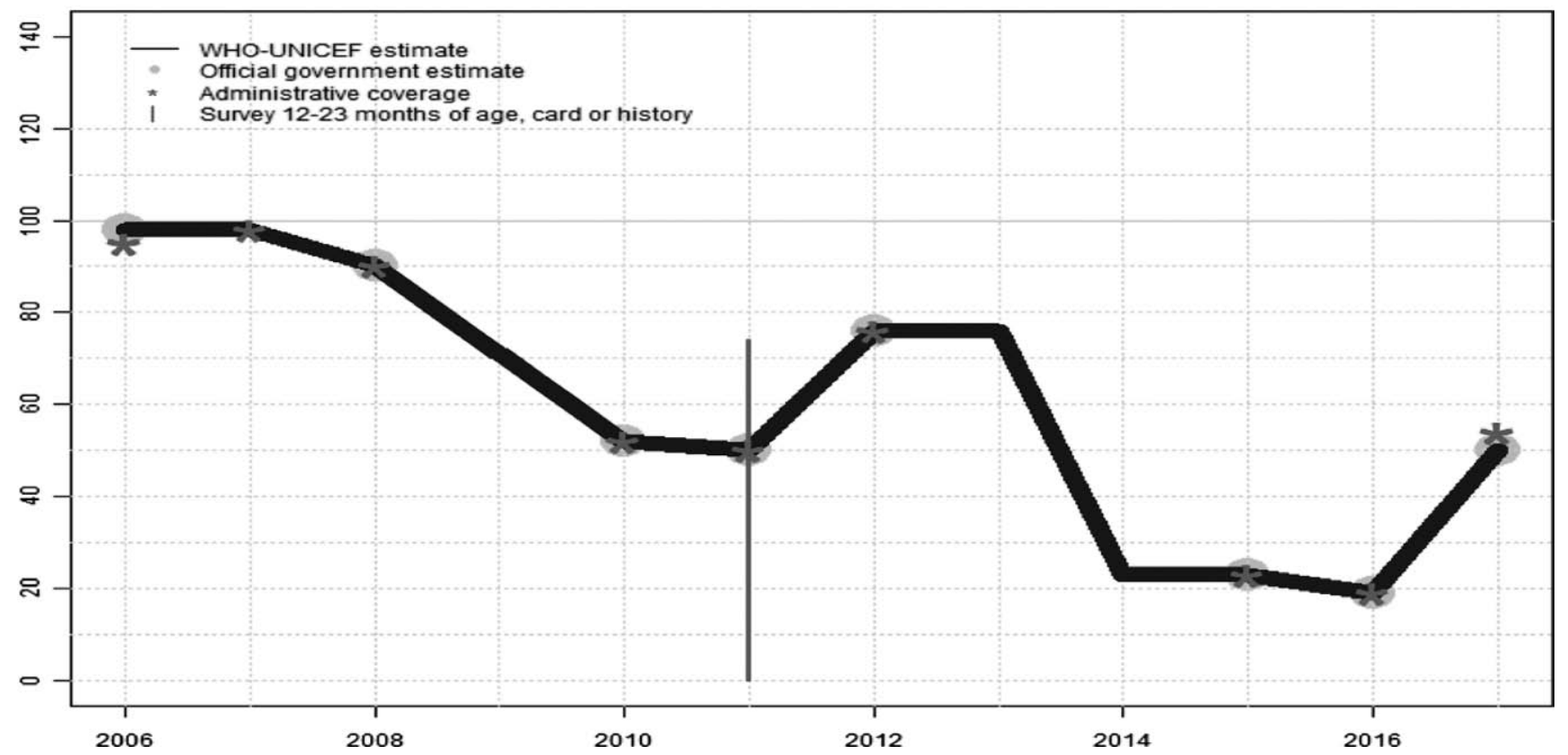

FIGURE 3. WHO and UNICEF estimates of national immunization coverage by DTP3, Ukraine, 2006-2016 (DTP3 = $3^{\text {rd }}$ dose of DTP vaccine according to vaccination schedule that should be administered at 6 months).

Source: http://www.who.int/immunization/monitoring_surveillance/data/ukr.pdf. 
could breathe spontaneously through his tracheostomy tube. The tracheostomy tube was removed on day 33, and the next day the patient was transferred to the neurological department for further rehabilitation.

\section{DISCUSSION}

Despite the fact that tetanus has become a rare pathology in developed countries due to successful implementation of the primary immunization programme, the risk of its development is still high because of low specific immunity in elderly people and persons not vaccinated due to religious or philosophical beliefs [6]. That is why some cases of tetanus are still registered in the United States of America. Eight cases of tetanus were registered in Canada during the 20082013 period $(7,8)$, and 126 cases in England and Wales during the 1984-1992 period (9).

In 2016, the WHO reported on 13,502 cases of tetanus in the world (against 10,377 in 2015), that were mainly connected with places of natural disasters such as earthquake, tsunami (Pakistan, Indonesia), and low-income countries, which do not have a complex immunization program (Somalia, Afghanistan, Kenya) and the mortality of neonates and toddlers is high $(2,10,11)$.

Fifteen cases of tetanus in children were registered in Ukraine in 2011-2015, and six cases in 2016 (12). The statistics is so sad and bad not only because of the interruption of vaccine provision, but also because of unwillingness of some parents to vaccinate their children.

According to the WHO definition, the main signs of tetanus are trismus (inability to open the mouth because of spasms in jaw muscles, risus sardonicus (progressive tonic spasm and contraction of mimic musculature with specific 'smile mask'), and painful muscular cramps; history of injury or wound is required, although tetanus is also known to occur even when there is no recall of trauma (13).

There are several clinical forms of tetanus in children: generalized, localized, cephalic and neonatal.

Generalized form occurs in 50\%-75\% of patients. Nuchal rigidity and dysphagia are early signs, together with trismus and risus sardonicus (14). Total muscular rigidity with periodical reflex contractions in response to minimal irritation develops in dynamics. Tonic contractions of muscles provoke opisthotonus. Patients feel severe pain during these episodes. Spasm may lead to fractures and tendon ruptures. Other symptoms include hyperthermia, hypersalivation, excessive sweating, fever, irritability, dyspnea and asphyxia, arrhythmia and cardiac arrest, uncontrolled urination or defecation. The mortality rate in the case of generalized tetanus can be as high as 70\%.
Patients with localized form of tetanus usually have persistent contraction of muscles near the site of trauma. Mortality is very low in these cases (15).

Cephalic form occurs usually after head trauma or otitis media and manifests with cerebral nerve palsy, which is usually combined with the signs of generalized form.

Neonatal tetanus is a generalized form of the disease that develops in newborns, usually those born to mothers who themselves have not been vaccinated. It usually occurs through infection of the unhealed umbilical stump or vessels, particularly when the stump is cut off with a non-sterile instrument. This form is the most lethal one; the mortality rate is near $90 \%$. Thanks to global immunization efforts, an estimated $85 \%$ of newborns were protected through immunization in 2017, but maternal and neonatal tetanus still persists as a public health problem in 14 countries, mainly in Africa and Asia (1).

The first signs of tetanus develop three days to three weeks after the infection penetration, when trismus, risus sardonicus, nuchal rigidity and dysphagia appear. Generalized tonic and clonic convulsions appear in 1-4 days.

Untimely diagnosis of the first signs of tetanus leads to breathing impairment, vegetative dysfunction that may end lethally. So, patients with clinically suspected tetanus should be hospitalized in a specialized ICU and should receive a multicomponent therapy, which includes primary surgical care, specific therapy with tetanus immunoglobulin (tetanus antitoxin), antibacterial, anticonvulsive and symptomatic therapy.

This discussion needs to address several important issues.

Firstly, this presentation underlines the necessity of planned immunization, which is a unique method to prevent tetanus, a life-threatening disease that leads to disability and may develop at any skin or mucosal trauma, if contaminated with Clostridium tetani spores that are singularly stable in the external environment. Poor immunization coverage in Ukraine is a big problem. Even the availability of sufficient amounts of DTP vaccine in the country during the last year could not solve this problem. The 2017 immunization coverage was only $50 \%$ because of a generally negative attitude and fears of parents. Despite the formation of vaccination support groups, the negative propaganda makes their efforts frequently unnoticed.

Secondly, because the prodromal period of clinical tetanus is usually mimicking an ENT disorder (dysphagia, trismus, and neck pain), it is important that various medical specialists maintain a high level of suspicion and readiness to get involved in the multidisciplinary management of the disease. 
Thirdly, this clinical case teaches us to solve another important problem, i.e. modern treatment of tetanus and main principles of its management $(13,16)$.

Current WHO recommendations include specific therapy with intramuscular tetanus immunoglobulin as soon as possible (10). For tetanus prophylaxis during wound management, a dosage of 250-500 IU is recommended for children older than 7 years; in adults, an additional age-adjusted tetanus toxoid containing vaccine, $0.5 \mathrm{cc}$, is administered by intramuscular injection at another site. For tetanus treatment, 3,000 to 6,000 IU intramuscularly as a single dose is administered within the first 24 hours of diagnosis; thus, a total dose of 500 units is now recommended by many authorities (17). For antibacterial therapy, metronidazole is preferred $(30 \mathrm{mg} / \mathrm{kg} /$ day, administered every six hours intravenously or by mouth) and penicillin $\mathrm{G}(100,000-200,000$ $\mathrm{IU} / \mathrm{kg} /$ day intravenously in 2-4 divided doses). Tetracyclines, macrolides, clindamycin, cephalosporins and chloramphenicol are also effective. The optimal management of tonic seizures in case of generalized tetanus requires ventilator support in the ICU plus one or more of the following: continuous infusion of midazolam, diazepam in a large dose (0.1-0.2 mg/kg/dose) every 2-6 hours, titrated upward as needed, propofol as a drug to potentiate sedation, and muscle relaxants are recommended $(18,19)$. Baclofen, dantrolene (1-2 mg/kg/every 4 hours), vecuronium (0.1 mg/ $\mathrm{kg} / \mathrm{h}$ ), barbiturates (short acting, in continuous i.v. infusion, 6-10 mg/kg/dose), and chlorpromazine (4-12 mg every 4-8 hours) are recommended among other medicines $(20,21)$. Magnesium sulphate is used both for muscular spasm control and for autonomic dysfunction management, $75 \mathrm{mg} /$ $\mathrm{kg}$ intravenous loading dose, then 2-3 grams per hour until spasm control is achieved (22). Morphine (1-2 mg/kg/every 12 hours) is used successfully for pain control and autonomic hyperreactivity control (21).

Rapid muscular mass loss develops in this group of patients because of excessive sympathetic activity and protein catabolism. A combination of parenteral and enteral feeding to restore metabolic losses is very important too (21).

\section{CONCLUSION}

Immunization is the single effective method to prevent tetanus; post-exposure prophylaxis could prevent generalized tetanus in those that were not immunized completely, or were immunized more than five years before. Early diagnosis of generalized tetanus in children remains a problem because of mimicking other disorders. Our clinical experience in the treatment of generalized tetanus in preschoolers according to modern European guidelines showed effectiveness of such treatment.

\section{REFERENCES}

1. WHO Health Topics: Immunization, Vaccines and Biologicals, Tetanus //http://www.who.int/immunization/monitoring_surveillance/burden/ $\mathrm{vpd} /$ surveillance_type/passive/tetanus/en/

2. Ukraine: WHO and UNICEF estimates of immunization coverage: 2017 revision; p. 1-17. http://www.who.int/immunization/monitoring surveillance/data/ukr.pdf.

3. Healthcare Ministry of Ukraine, Public Health Centre, Diseases and Information, Immunization Coverage. http://phc.org.ua/pages/diseases/ immunization/immunization-coverage

4. Order of the Healthcare Ministry of Ukraine No. 198 as of Aug 5, 1999. On improvement of prevention, diagnosis and treatment of tetanus. (in Ukrainian). http://mozdocs.kiev.ua/view.php?id=776.

5. Korsunska Ol, Nefiodov OO. Immunotropic drugs in the work of a general practitioner (pharmacotherapeutic guide). Dnipropetrovsk: Lithograph, 2015; p. 13. (in Ukrainian)

6. de Jong RP, Heer-Groen T, Cornelis H, Schröder NJ, Jansen G. Generalized tetanus in a 4-year-old boy presenting with dysphagia and trismus: a case report, 2009. https://casesjournal.biomedcentral.com/ articles/10.1186/1757-1626-2-7003.

7. Public Health Agency of Canada. Tetanus, 2014. http://www.phacaspc. gc.ca/im/vpd-mev/tetanus-tetanos/professionalsprofessionnels-eng.php.

8. Government of Canada. Tetanus toxoid. In: Canadian Immunization Guide 2016. https://www.canada.ca/en/publichealth/services/publications/ healthy-living/canadianimmunization-guide-part-4-active-vaccines/ page-22-tetanus-toxoid.html.

9. Rushdy AA, White JM, Ramsay ME, Crowcroft NS. Tetanus in England and Wales, 1984-2000. Epidemiol Infect. 2003;130:71-7.

10. World Health Organization. Immunization, Vaccines and Biologicals: Tetanus, 2017. http://www.who.int/immunization/monitoring_ surveillance/burden/vpd/surveillancetype/passive/ tetanus/en.

11. Kyu HH, Mumford JE, Stanaway JD, et al. Mortality from tetanus between 1990 and 2015: findings from the global burden of disease study 2015 BMC Public Health 2017;17:179.

12. Motyka Ol, Henyk ID, Slesarchuk OM, Malova OS, Pavliy RB. The signs of tetanus epidemiological activation in Ukraine in the recent period. Aktual'na Infektologiya. 2017;5:250-2. doi: 10.22141/2312413x.5.5.2017.121640

13. Current recommendations for treatment of tetanus during humanitarian emergencies, WHO Technical Note, 2010. http://www.who.int/ diseasecontrol_emergencies/publications/who_hse_gar_dce_2010.2/en/

14. Pearce JM. Notes on tetanus (lockjaw). J Neurol Neurosurg Psychiatry. 1996;60:332.

15. Manual for the Surveillance of Vaccine-Preventable Diseases. Chapter 16 Tetanus. Centers for Disease Control and Prevention, 2014. http://www.cdc.gov/vaccines/pubs/surv-manual/chpt16-tetanus.html.

16. Communicable Disease Management Protocols, 2017. http://www.gov.mb.ca/health/publichealth/cdc/protocol

17. Plotkin SA, Orenstein WA, Offit PA, Edwards KM. Plotkin's Vaccines, $7^{\text {th }}$ edn. Elsevier, 2017; p. 1056

18. Orko R, Rosenberg PH, Himberg JJ. IV infusion of midazolam, propofol and vecuronium in a patient with severe tetanus. Acta Anaesthesiol Scand. 1988;32:590-2.

19. Petitjeans F, Turc J, Coulet O, Puidupin M, Eve O, Benois A. The use of boluses of propofol for the management of severe tetanus in a child. Trop Doct. 2009;39:52-3.

20. Boots RJ, Lipman J, O'Callaghan J, Scott P, Fraser J. The treatment of tetanus with intrathecal baclofen. Anaesth Intensive Care. 2000;28:438-41.

21. Abdelmoneim T, DeNicola LK, Hasan MY. Tetanus: complications and management in a Pediatric Intensive Care Unit. In: Rare Case Registry of PedsCCM: The Pediatric Critical Care Web Site, 1997. http://pedsccm.org / RARE/Tetanus.html.

22. Rodrigo C, Samarakoon L, Fernando SD, Rajapakse S. A meta-analysis of magnesium for tetanus. Anaesthesia. 2012;67:1370-4. 


\section{SAZ̈ETAK}

\section{Tetanus u djeteta kao rezultat nepoštivanja kalendara cijepljenja - prikaz slučaja}

Halyna Pavlyshyn, Ivanna Horishna, Viktoriia Slyva

Analiziran je klinički slučaj generaliziranog tetanusa u predškolskog djeteta kod kojega se nije poštivao kalendar cijepljenja. Opisani su klinički znakovi teškog generaliziranog tetanusa. Prikazani su suvremeni pristupi liječenju ovakovih bolesnika, učinkovitost i očekivana dobrobit terapije.

Ključne riječi: TETANUS; DJECA; LIJEČENJE 